\title{
Traduzindo Nerval
}

\author{
ALEXEI BUENO
}

$\mathrm{N}$

O ANO de 1990, traduzi os vinte sonetos que compõem a série completa de Les chimères de Nerval, ou seja, os doze sonetos que levam exatamente esse título, juntamente com os oito outros que constituem as Autres chimères, um conjunto de uma unidade evidente, uma totalidade a ser mantida.

Fiz a tradução a partir de um convite de meu amigo Marco Lucchesi, que pretendia publicar uma edição bilíngue pela editora carioca Numen. Para minha surpresa, a tradução fluiu com muita rapidez, sendo os vinte sonetos vertidos para a nossa língua entre os dias 12 e 16 de março daquele ano. Além da primeira edição de 1990, tal tradução teve uma edição portuguesa em 1995, pela Hiena Editora, de Lisboa, e uma segunda edição brasileira pela editora Topbooks, do Rio de Janeiro, em 1996, o que demonstra uma boa recepção. Ainda no presente ano a série reaparecerá no meu livro Cinco séculos de poesia: poemas traduzidos, pela Editora Record.

Sobre o meu interesse pessoal em Gérard de Nerval, e especialmente em Les chimères, creio que a melhor ilustração possível se encontra no seguinte trecho do prefácio ao livro:

O primeiro Nerval a ser conhecido foi o tradutor de Goethe. O segundo o poeta amável das "Odelettes", o autor de lieder alemães em língua francesa, o lírico delicado dos Petits châteaux de Bohème. O terceiro, e o maior e definitivo, é o visionário, o louco, real e não apenas literário, o criador de mitologias de Aurélia e de "As Quimeras”. Como com o Hölderlin da última fase, o preço da travessia do portal que se abre ao mundo invisível foi a loucura, assim como com William Blake ou Swedenborg, com a possível ressalva de os loucos sermos nós. Em nenhum desses casos chegáramos ainda à decisão racional e pré-surrealista de se tornar um "vidente", como fez Rimbaud, através de um desregramento geral de todos os sentidos teorizado e procurado.

Entramos assim na controversa relação entre gênio e loucura. Poucas obras poéticas, em toda a literatura francesa, deram origem a tão vasta bibliografia como essas duas dezenas de sonetos, na verdade menos que isso, se considerarmos os que são quase variações de outros e partes de outros, estranhamente permutadas. Na tentativa vã de encontrar uma interpretação definitiva todas as doutrinas e escolas de pensamento foram chamadas, da Alquimia à Psicanálise, da Cabala ao Orfismo, da Teosofia à Numerologia, sem que nunca se tenha chegado a um resultado totalmente convincente. De fato, a pan-religiosidade das “As Quimeras”, a sua antiortodoxia em relação a qualquer sistema são os índices infalíveis da derrota de toda tentativa 
de interpretação absoluta. Pois, mais do que a afirmação da existência de determinada verdade oculta, essa poesia originalíssima é a própria verdade oculta, que se realiza mas não se desvela. Através dela entramos num mundo de sensibilidade desconhecido para nós. Depois dela, apesar de sabermos que lá estivemos, ela permanece desconhecido. Esse é um milagre típico da arte, a possibilidade de penetrar o mistério sem desvendá-lo, o que significaria destruí-lo. E como não perceber que o grande significado intrínseco do mistério é a sua própria permanência, tal como ele é, na iminência potencial de um desvendamento que é o seu predicado mais autêntico.

Figura dócil e discreta do grande momento do Romantismo, biograficamente tendendo a um estado de rêverie muito comum até em individualidades bem secundárias daquele período, Nerval foi pouco a pouco - nutrido de todas as frustrações pessoais e sonhos não cumpridos que acompanham qualquer homem, além de uma continuada leitura dos grandes textos iniciáticos - abrindo a brecha na grande muralha da realidade concreta e indivisível, através da qual, nos seus últimos anos de vida, conceberia o estranho coroamento de sua obra. Em “As Quimeras”, mais do que a estetização de qualquer doutrina, encontramos um puro e intocado anelo do sagrado, alimentado indiscriminadamente por todas as suas manifestações externas, mesmo antagônicas. Idêntico anelo do sagrado é o que encontramos, por exemplo, nos belíssimos e hieráticos poemas egípcios de Ângelo de Lima, divulgados no primeiro número de Orfen, em 1915.

Nerval, alimentado havia muito por leituras ocultistas, gnósticas, pitagóricas e cabalistas, além do ambiente romântico favorável a todo o fantástico, viveu pessoalmente o mergulhos na floresta das analogias arquetípicas, das simbologias delirantes. Anos depois, numa experiência semelhante, Strindberg vagaria pelas mesmas ruas de Paris procurando, nos menores incidentes, um sinal escapado da verdadeira ordem oculta do mundo, a autêntica frente da tapeçaria, da qual vemos apenas o reverso, e que é a verdadeira origem e determinação de tudo que nos acontece.

Entrando, como um arqueólogo, no anfiteatro das ciências mortas, tocado para lá por suas frustrações amorosas, biográficas ou outras necessidades mais obscuras e profundas, Nerval se encontra no meio de ruínas da todas as religiões, templos derruídos, estátuas derrubadas, inscrições mutiladas, estranhas arquiteturas sacras de cultos desconhecidos ou mesmo inconciliáveis, mas que, no entanto, se misturaram no trovão ensurdecedor e escuro de suas quedas concomitantes, perante a pretensa invasão da razão de um século de luzes.

Nesse chão juncado de humanidade há símbolos cristãos revestindo deuses egípcios, árvores gregas sagradas crescendo sobre fundamentos de zigurates babilônicos, cordas de liras órficas enroscadas aos rosários de santas peninsulares, e a noite eterna da alma, como uma única catedral indescritível, crescendo sobre tudo.

Ele então, já o criador de genealogias alucinadas, descendente de persas 
e de cruzados, de troncos napoleônicos e normandos, como um grande iluminado, como um que realmente em sua vida passou pela experiência do desdobramento, a visão de que todo este universo é apenas um lado da moeda, ali penetra, como um novo arquiteto, para reconstruir, em duas dezenas de sonetos, em duas dezenas de "Quimeras", o seu templo órfico-céltico-egípcio-pitagórico-cabalístico-cristão, onde ele mesmo, com o sangue mitologicamente nobre que corre em suas veias, é o neófito e o mestre, o sacrificador e a vítima, o sacerdote e o ídolo oculto.

Aí estão as fadas e as rainhas, os dragões mortos e os deuses vingadores, as santas e as grotas impenetráveis, dos quais só uma mente tem a visão e o segredo. E dessa confusão de todos os arquétipos, desta corrida alucinada de todas as analogias, desta compensação sagrada de todas as limitações de nossa vida miserável, desta série de quadros de Gustave Moreau pintados com palavras antes que Moreau os pintasse, emergem, pela primeira vez, e nunca tão claramente, o Simbolismo, fonte de toda a poesia moderna, e o Surrealismo, que sempre de alguma maneira impregnou toda a literatura que lhe sucedeu.

Este é o sacerdote e estes seus altares. Este é Nerval e "As Quimeras".

Nessa empreitada segui o caminho que sempre me propus na tradução de poesia, ou seja, a manutenção mais estrita da forma do original, métrica e rimicamente, quando fosse o caso, e ritmicamente, em todos eles, a mesma posição no assunto, para usar o mais prestigioso dos exemplos, de Fernando Pessoa. Como antes afirmei, a tradução ocorreu com muita facilidade, talvez pela índole próxima das línguas. Nos variados poemas que traduzi, majoritariamente do inglês, do francês, do italiano e do espanhol - este bem menos que os outros, por sua grande proximidade com o português me dar comumente a impressão da pouca utilidade das traduções - esse nível de fluência, de maior ou menor facilidade, sempre variou muito. Em língua inglesa, por exemplo, a tradução que fiz do poema "Excelsoir", de Longfellow, fluiu com uma naturalidade assombrosa, redundando num muito belo poema romântico em português, tal como é o seu original. Já a tradução da "The charge ot the Light Brigade", de Tennyson, parece-me ter sido a mais difícil de quantas fiz até hoje, entre outros motivos por ser um poema em versos curtos, e numa língua com as palavras comumente mais curtas do que as nossas, uma língua de forte tendência monossilábica como é o inglês.

Ao me propor a traduzir os doze sonetos de Nerval, de início tomei uma decisão que me parece acertada, traduzi-los em dodecassílabos, mas não obrigatoriamente em alexandrinos, como o original. Os dodecassílabos acentuados na sexta e, obviamente, décima segunda sílabas, me pareceram mais próximos da índole da nossa língua do que o alexandrino, cuja obrigação do hemistíquio poderia dificultar a recuperação de outros valores muito mais importantes dos poemas. $\mathrm{O}$ alexandrino, de fato, sempre foi um verso transplantado artificialmente para o português, sendo da maior naturalidade, no entanto, numa língua com um léxico de tendência fortemente oxítona como é a francesa. 
Obviamente, em muitos casos os dodecassílabos também eram alexandrinos, mas nunca de maneira procurada. Como exemplo reproduzo o primeiro, e provavelmente o mais célebre soneto da série, no original e na respectiva tradução (12.3.1990):

\section{EL DESDICHADO}

Je suis le Ténébreux, _ le Veuf, _l'Inconsolé,

Le prince d'Aquitaine à la tour abolie:

Ma seule étoile est morte, _et mon luth constellé

Porte le soleil noir de la Mélancolie.

Dans la nuit du tombeau, toi qui m'as consolé,

Rends-moi le Pausilippe et la mer d'Italie,

La fleur qui plaisait tant à mon coeur désolé

Et la treille où le pampre à la rose s'allie.

Suis-je Amour ou Phébus?... Lusignan ou Biron? Mon front est rouge encor du baiser de la reine; J'ai rêvé dans la grotte où nage la sirène...

Et j'ai deux fois vainqueur traversé l'Achéron: Modulant tour à tour sur la lyre d'Orphée

Les soupirs de la sainte et les cris de la fée.

\section{EL DESDICHADO}

Eu sou o Tenebroso, _ o Viúvo, _ o Inconsolado, O Senhor de Aquitânia à Torre da Abulia:

Meu único Astro é morto, e o meu alaúde iriado

Irradia o Sol negro da Melancolia.

Na noite Sepulcral, Tu que me hás consolado,

O Posílipo e o mar Itálico me envia,

A flor que tanto amava o meu ser desolado,

E a treliça onde a Vinha à Roseira se alia.

Sou Biron, Lusignan?... Febo ou Amor? Na fronte

Ainda o beijo da Rainha rubro me incendeia;

Eu sonhei na caverna onde nada a Sereia...

E duas vezes cruzei vencedor o Aqueronte:

Modulando na cítara a Orfeu consagrada

Os suspiros da santa e os arquejos da Fada. 


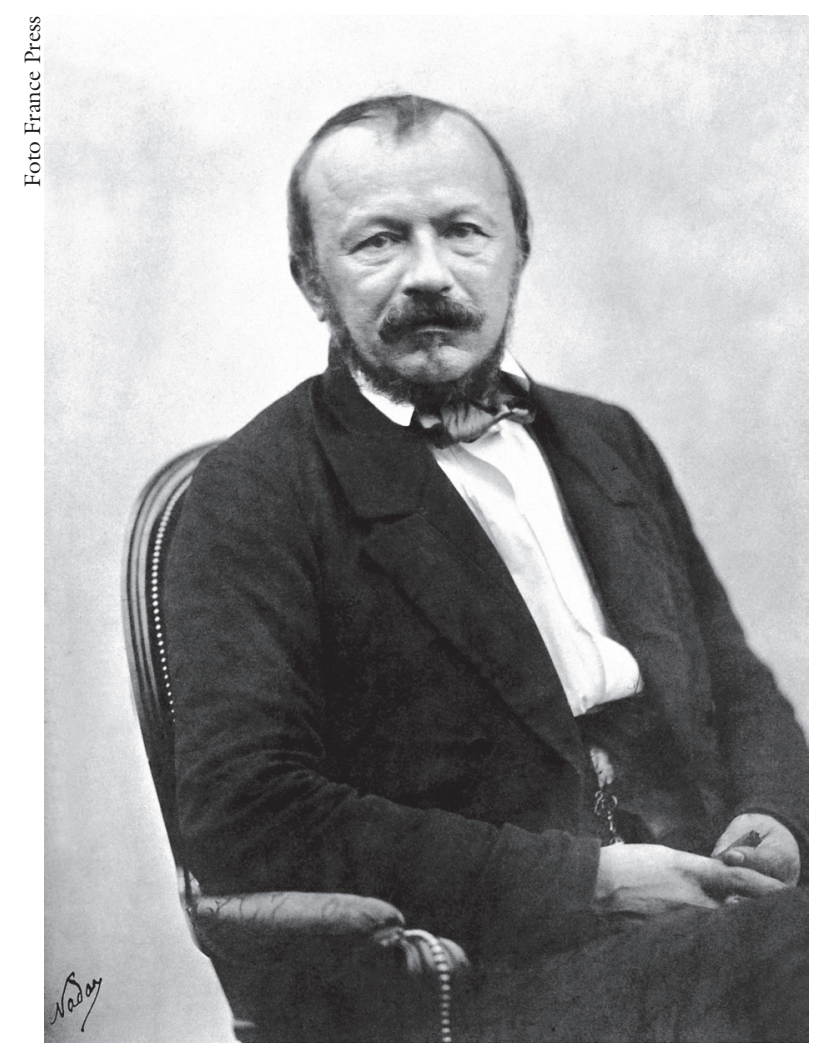

Gérard de Nerval (1808-1855).

Como podemos ver, nove dos quatorze versos são alexandrinos, simplesmente por assim terem saído na tradução, e três deles, os versos 4, 10 e 13, são simplesmente dodecassílabos. Quando do lançamento da segunda edição brasileira, um crítico, visivelmente infenso à tradução poética que tenta manter a forma do original, fez grande caso da desaparição da palavra "abolie" no segundo verso da versão portuguesa. Eu, muito ao contrário, acho a solução "Torre da Abulia" altamente satisfatória, primeiro pela forte ambiência simbolista que emana dessa expressão, depois porque, sendo a abulia a ausência de vontade, a ausência de ação, e tudo o que existe, de certa maneira, consistir em ação e vontade, tal palavra me parece muito exata para tomar o lugar de "abolie". A recuperação dos valores sonoros, encantatórios, da forma do poema, parece-me compensar fartamente esses pequenos afastamentos do significado, e ainda muito mais no caso de Nerval.

Existem duas definições de poesia que muito me agradam. A primeira, atribuída a Paul Valéry, afirma ser ela uma indecisão entre um som e um sentido. A segunda afirma que a poesia é a arte de dizer apenas com palavras o que apenas palavras não podem dizer. Em ambos os casos a tradução poética dos poemas me perece ser a única que se justifica.

Como podemos ver também no soneto que escolhemos como exemplo, o primeiro verso saiu em português sem qualquer esforço, diretamente, um alexandrino perfeito com as mesmas exatas palavras do original. Já no segundo verso apareceu a dificuldade que acabamos de analisar. 
Para finalizar esta breve rememoração da minha experiência de tradutor de Gérard de Nerval, reproduzo, de forma aleatória, um outro soneto das "Quimeras", no caso o primeiro de uma série de cinco, um ciclo dentro de outro ciclo, o terrível "Le Christ aux Oliviers", que me parece demonstrar a grande semelhança com o original, na forma e no fundo, que pode atingir a tradução de poesia:

\section{LE CHRIST AUX OLIVIERS \\ (Imité de Jean-Paul)}

Dieu est mort! le ciel est vide...

Pleurez! enfants, vous n'avez plus de père!

JEAN-PAUL

I

Quand le Seigneur, levant au ciel ses maigres bras,

Sous les arbres sacrés, comme font les poètes

Se fut longtemps perdu dans ses douleurs muettes,

Et se jugea trahi par des amis ingrats,

Il se tourna vers ceux qui l'attendaient en bas

Rêvant d'être des rois, des sages, des prophètes...

Mais engourdis, perdus dans le sommeil des bêtes,

Et se prit à crier: "Non, Dieu n'existe pas!"

Ils dormaient. "Mes amis, savez-pous la nouvelle?

J'ai touché de mon front à la voûte éternelle;

Je suis sanglant, brisé, souffrant pour bien des jours!

Frères, je vous trompais: Abîme! abîme! abîme!

Le dieu manque à l'autel où je suis la victime...

Dieu n'est pas! Dieu n'est plus!" Mais ils dormaient toujours!...

\section{O CRISTO NO HORTO DAS OLIVEIRAS}

(Imitado de Jean-Paul)

Dieu est mort! le ciel est vide...

Pleurez! enfants, vous n'avez plus de père!

JEAN-PAUL

\section{I}

Quando o Senhor, erguendo aos céus seus magros braços,

Sob as árvores santas, tal como os poetas,

Perdeu-se longamente entre dores secretas,

E traído se achou por seus amigos lassos; 
Voltou-se aos que o esperavam, vindos nos seus passos,

Sonhando em serem reis, ou sábios, ou profetas...

Mas tontos a dormir, iguais a bestas quietas,

E gritou: "Não há Deus!” bem alto nos espaços.

Dormiam. "Meus amigos, conheceis a nova?

Toquei com minha fronte o alto da eterna cova:

Quebrado, há muito eu sofro, e o meu sangue vai fluindo!

Irmãos, vos enganei. Abismo! abismo! abismo!

Falta o deus a esse altar onde, vítima, eu cismo...

Não há Deus! Deus não é!” E eles sempre dormindo!

16.3.1990

Como podemos ver, nem a tradução de poesia, ao menos em muitos casos, é uma tarefa impossível, nem o tradutor tem que ser o traidor do celebérrimo jogo de palavras.

RESUMO - O artigo descreve a experiência do autor traduzindo Gérard de Nerval "Les chimères", em 1990, e apresenta as suas ideias sobre a tradução de poesia.

PALAVRAS-CHAVE: Gérard de Nerval, Tradução, Poesia.

ABSTRACT - The article describes the author's experience translating Gérard de Nerval's "Les chimères" in 1990, and sets forth his ideas on the translation of poetry.

KEYWORDS: Gérard de Nerval, Translation, Poetry.

Alexei Bueno é poeta. Publicou, entre outros livros, As escadas da torre (1984); Poemas gregos (1985); Livro de haicais (1989); A decomposição de J. S. Bach (1989); Lucernário (1993); A via estreita (1995 - Prêmio Alphonsus de Guimaraens, da Biblioteca Nacional, e Prêmio da APCA); A juventude dos deuses (1996); Entusiasmo (1997); Poemas reunidos (1998 - Prêmio Fernando Pessoa); Em sonho (1999); Os resistentes (2001); Gamboa (2002), para a coleção Cantos do Rio; O patrimônio construido (2002, com Augusto Carlos da Silva Teles e Lauro Cavalcanti - Prêmio Jabuti); Glauber Rocha, mais fortes são os poderes do povo! (2003); Poesia reunida (2003 - Prêmio Jabuti, Prêmio da Academia Brasileira de Letras). @- alexei@academia.org.br

Recebido em 10.9.2012 e aceito em 20.9.2012. 
